\title{
GAD65 Positive Autoimmune Limbic Encephalitis: A Case Report and Review of Literature
}

\author{
Abhishek Sharma $^{\mathrm{a}, \mathrm{d}}$, Divyanshu Dubey ${ }^{\mathrm{b}}$, Anshudha Sawhney ${ }^{\mathrm{c}}$, Kalyana Janga ${ }^{\mathrm{a}}$
}

\begin{abstract}
Limbic encephalitis is a rare disorder affecting the medial temporal lobe of the brain, sometimes also involving hippocampus atrophy. It was initially considered to be only of paraneoplastic origin but now auto-immune (non-paraneoplastic) cases have also been reported. Most common non paraneoplastic antibodies associated with limbic encephalitis are Voltage gated potassium channel antibodies, NMDA receptor antibodies and GAD receptor antibodies. We present a case of limbic encephalitis which presented with sudden onset seizures which was preceded by confusion, disorientation and other psychiatric symptoms for a period of 5 weeks. No tumor was found on imaging and the classic paraneoplastic panel was negative. CSF and serum examination showed high titers GAD65 antibody guiding towards a diagnosis of non paraneoplastic limbic encephalitis. Her symptoms and GAD 65 antibody titers showed significant improvement following immunomodulatory therapy. The case presented here is unique and scientifically relevant, as it intends to raise awareness of Auto-immune Limbic Encephalitis, a potentially reversible cause of a medical emergency.
\end{abstract}

Keywords: Autoimmune; Limbic encephalitis; GAD Antibody; Seizure

\section{Introduction}

The field of medicine is filled with multiple challenges. Few of the challenges are related to the diagnosis of the underly-

\footnotetext{
Manuscript accepted for publication July 26, 2012

${ }^{\mathrm{a}}$ Department of Medicine, Maimonides Medical Center, New York, USA

${ }^{\mathrm{b}}$ Department of Neurology, UT Southwestern, Texas, USA

${ }^{\mathrm{c}}$ Department of Medicine, Pt. Madan Mohan Malviya Hospital, New Delhi, India

${ }^{\mathrm{d}}$ Corresponding author: Abhishek Sharma, 1016 50th Street Apt 2C, Brooklyn, NY 11219, USA.

Email: abhisheksharma4mamc@gmail.com
}

doi: http://dx.doi.org/10.4021/jocmr1080w ing condition, others pertaining to restricted therapeutic options. Limbic encephalitis (LE) as a pathology poses both these challenges. Myriad of clinical presentation and lack of symptom specificity including seizure, memory problems, irritability, depression, confusion and dementia leads to a wide differential diagnosis [1]. Viral infections, inflammatory or autoimmune disorders (lupus, Sjogren's, Hashimoto thyroiditis and CNS vasculitis), toxic and metabolic encephalopathies, and paraneoplastic syndromes become the possible clinical etiologies.

Limbic encephalitis is a rare disorder affecting the medial temporal lobe of the brain, sometimes also involving hippocampus atrophy. It was first described by Breirly et al in 1960s when they reported 3 cases of sub-acute encephalitis involving the limbic area [2]. In 1968 Corsellis et al coined the term "limbic encephalitis" and also established the relationship between limbic encephalitis and systemic cancer [3]. Inflammatory involvement of the limbic area of the brain can also be explained by infective (viral) and systemic autoimmune (Sjogren's syndrome, systemic lupus erythmatosus, hashimoto thyroid it's, sarcoidosis) etiologies. Many neuronal antibodies have been associated with LE. These can be directed either against intracellular (classic paraneoplastic) antigens, including $\mathrm{Hu}, \mathrm{CV} 2 / \mathrm{CRMP} 5, \mathrm{Ma} 2$ and amphiphysin or against cell membrane antigens, including voltagegated potassium channels, N-methyl-D-aspartate receptor and Glutamic Acid Decarboxylase receptors expressed in the neuropil of hippocampus and cerebellum $[4,5]$. The former category is related to cancer (paraneoplastic limbic encephalitis), showing limited response to immunomodulatory therapy whereas the latter category is less frequently associated with tumors and responds significantly better to immunomodulatory therapy. It has also been recognized that some patients presenting with limbic encephalitis with negative antibody screen in serum and CSF show full recovery after treatment with steroids or immunomodulatory therapy indicating an autoimmune etiology $[6,7]$. We present a case of a patient with rapidly deteriorating cognitive function and recurrent seizures. She was diagnosed with autoimmune limbic encephalitis associated with GAD65 antibodies. Her symptoms showed dramatic improvement following immunomodulatory therapy. The case presented here is unique 
and scientifically relevant, as it intends to raise awareness of Auto-immune Limbic Encephalitis, a potentially reversible cause of a medical emergency.

\section{Case Report}

A 22-year-old right handed woman without any significant past medical history presented with episodes of sudden onset seizures, inability to recognize immediate family members and familiar places, apathy, bizarre behaviors, and brief episodes of disorientation for 5 weeks. On examination she was scored 24/30 on Mini-mental state examination. Cranial nerve, language, sensory, motor and cerebellar function test were within normal limits. MRI showed bilateral signal hyper intensity in temporal lobes.

Lumbar puncture was performed and CSF analysis showed no pleocystosis and CSF protein and glucose were within normal limit. PCR for HSV and HHV-6 was negative. Seizure episodes were documented on video-EEG monitoring. Psychiatry expert were also consulted which ruled out any psychiatric disorder for patient symptoms. A diagnostic search for cancer including imaging and serological studies for various tumor markers was negative. Evaluation of typical antibodies (Hu, CV2/CRMP5 and Ma2 etc.) present in a paraneoplastic panel also turned out to be negative. Autoantibody markers in CSF and serum showed presence of presence of GAD65 autoantibody, but evaluation of NMDA receptor antibodies and Voltage gated potassium channel antibody (VGKc) was negative. Suspecting an autoimmune etiology immunomodulatory treatment with intravenous immunoglobulin and intravenous methyl-prednisone was initiated, which subsequently resulted in marked improvement in symptoms. Subsequent assessment of GAD65, post-immunomodulatory therapy showed a decrease in titers of GAD65 antibody.

\section{Discussion}

Limbic encephalitic syndrome presents as a diagnostic challenge. Classic presentation includes the rapid development of irritability, short-term memory loss, depression, sleep disturbances, hallucinations and seizures. Confusion, repetition of same questions over and over, staring episodes and involvement of temporal lobe is hallmark of LE patients. Autobiographical memory is characteristically preserved in this disorder. LE usually has a sub-acute development, in days or weeks, presenting initially as short-term memory deficits, but this deficit is surprisingly overlooked in some patients [1].

Initial investigation in these patient commonly include CT of the brain with contrast, LP with cell count, protein, glucose (and serum glucose), viral screen (especially HSV, 


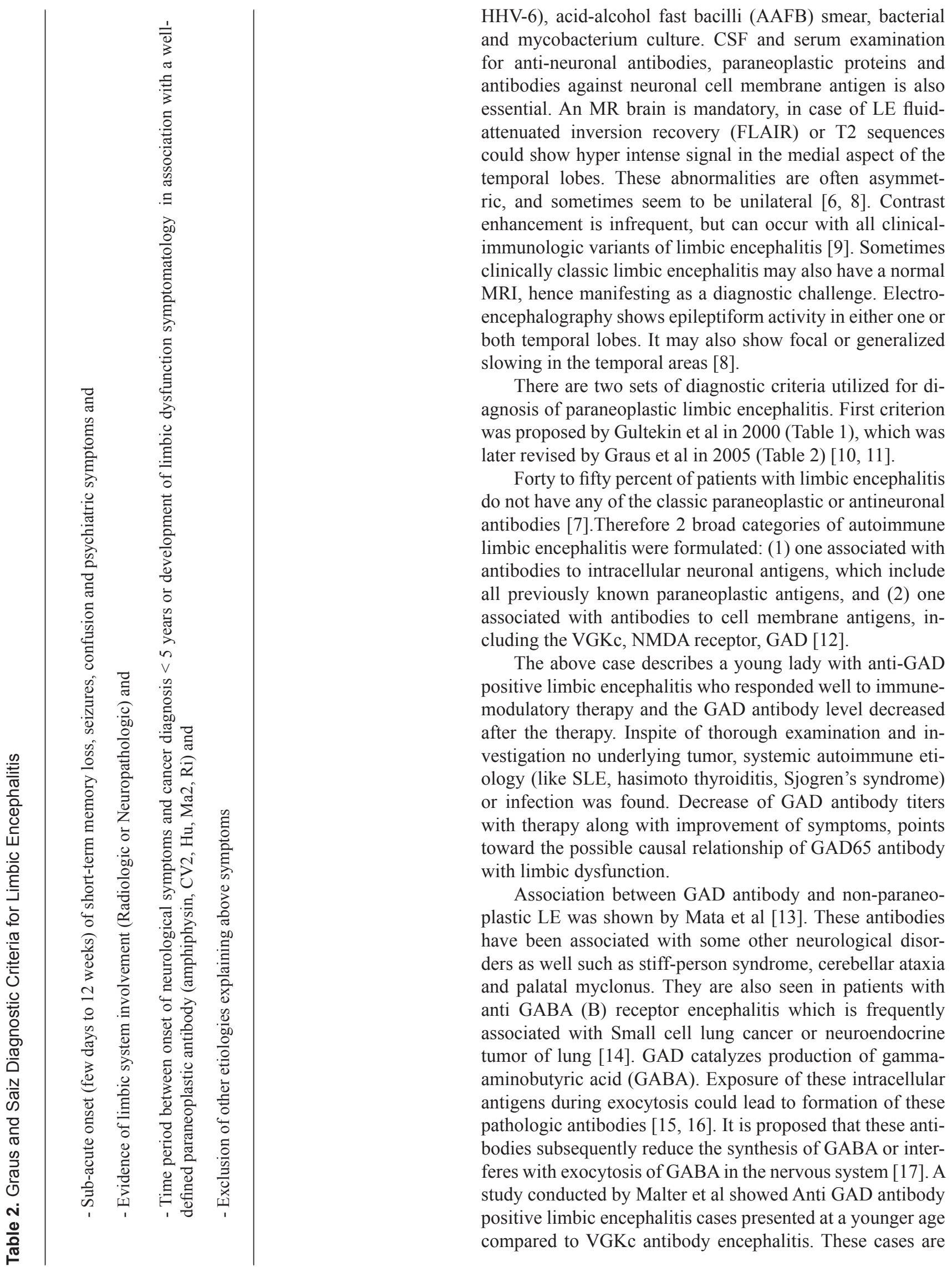


more commonly found in females than males. Common initial presentation is seizure, which remains resistant to anticonvulsive therapy [18]. Other studies have shown patients with GAD antibody LE presenting initially with short term memory loss [19].

Corticosteroids, intravenous immunoglobulin and plasma exchange are most frequently used as therapeutic options. Other immune-suppressive agents like cyclophosphamide and rituximab can also be utilized as a therapeutic option $[7,20]$. GAD antibody LE patients are far more resistant to methyl prednisone treatment compared to VGKc antibody LE patients. But these patients have responded well to intravenous immunoglobulin and plasma exchange [13, 21]. A study conducted by Saidha et al also shows promising results with decrease in seizure frequency and improvement in Behavior memory testing in these patients with use of mycophenolate mofetil [22]. Development of these therapeutic options highlights the need for early detection and aggressive management for patients with autoimmune limbic encephalitis. If this disease process is considered early, diagnosed promptly and treated appropriately, it can be reversed and the patient restored to their premorbid state.

\section{Conclusion}

Limbic encephalitis, when initially discovered in 1960s was believed to be exclusively of paraneoplastic origin, but there have been an increasing frequency of cases in adults and pediatric population without evidence of a tumor at presentation. Anti-GAD receptor antibody-positive limbic encephalitis is an emerging diagnosis amongst the adult population. It is important that we consider autoimmune limbic encephalitis in our differential diagnosis in adults with encephalopathy, particularly if psychiatric symptoms are seen. Therapeutic responsiveness of this condition reiterates the importance of diagnosing a reversible neurologic pathology. With timely intervention, clinicians may be able to avoid permanent cognitive and behavioral damage.

\section{Conflict of Interest}

All authors declare no conflict of interest.

\section{Source of Funding}

None.

\section{References}

1. Tuzun E, Dalmau J. Limbic encephalitis and variants: classification, diagnosis and treatment. Neurologist.
2007;13(5):261-271.

2. Brierley JB, Corsellis JAN, Hierons R, et al. Subacute encephalitis of later adult life. Mainly affecting the limbic areas. Brain. 1960; 83:357-368.

3. Corsellis JA, Goldberg GJ, Norton AR. "Limbic encephalitis" and its association with carcinoma. Brain. 1968;91(3):481-496.

4. Anderson NE, Barber PA. Limbic encephalitis - a review. J Clin Neurosci. 2008;15(9):961-971.

5. Florance NR, Davis RL, Lam C, Szperka C, Zhou L, Ahmad S, Campen CJ, et al. Anti-N-methyl-D-aspartate receptor (NMDAR) encephalitis in children and adolescents. Ann Neurol. 2009;66(1):11-18.

6. Urbach H, Soeder BM, Jeub M, Klockgether T, Meyer B, Bien CG. Serial MRI of limbic encephalitis. Neuroradiology. 2006;48(6):380-386.

7. Bataller L, Kleopa KA, Wu GF, Rossi JE, Rosenfeld MR, Dalmau J. Autoimmune limbic encephalitis in 39 patients: immunophenotypes and outcomes. J Neurol Neurosurg Psychiatry. 2007;78(4):381-385.

8. Lawn ND, Westmoreland BF, Kiely MJ, Lennon VA, Vernino S. Clinical, magnetic resonance imaging, and electroencephalographic findings in paraneoplastic limbic encephalitis. Mayo Clin Proc. 2003;78(11):13631368.

9. Fadul CE, Stommel EW, Dragnev KH, Eskey CJ, Dalmau JO. Focal paraneoplastic limbic encephalitis presenting as orgasmic epilepsy. J Neurooncol. 2005;72(2):195198.

10. Gultekin SH, Rosenfeld MR, Voltz R, Eichen J, Posner JB, Dalmau J. Paraneoplastic limbic encephalitis: neurological symptoms, immunological findings and tumour association in 50 patients. Brain. 2000;123 ( Pt 7):14811494.

11. Graus F, Saiz A. [Limbic encephalitis: a probably underrecognized syndrome]. Neurologia. 2005;20(1):24-30.

12. Bien CG, Elger CE. Limbic encephalitis: a cause of temporal lobe epilepsy with onset in adult life. Epilepsy Behav. 2007;10(4):529-538.

13. Mata S, Muscas GC, Naldi I, Rosati E, Paladini S, Cruciatti B, Bisulli F, et al. Non-paraneoplastic limbic encephalitis associated with anti-glutamic acid decarboxylase antibodies. J Neuroimmunol. 2008;199(12):155-159.

14. Lancaster E, Lai M, Peng X, Hughes E, Constantinescu R, Raizer J, Friedman D, et al. Antibodies to the GABA(B) receptor in limbic encephalitis with seizures: case series and characterisation of the antigen. Lancet Neurol. 2010;9(1):67-76.

15. Reetz A, Solimena M, Matteoli M, Folli F, Takei K, De Camilli P. GABA and pancreatic beta-cells: colocalization of glutamic acid decarboxylase (GAD) and GABA with synaptic-like microvesicles suggests their role in GABA storage and secretion. EMBO J. 
1991;10(5):1275-1284.

16. Christgau S, Aanstoot HJ, Schierbeck H, Begley K, Tullin S, Hejnaes K, Baekkeskov S. Membrane anchoring of the autoantigen GAD65 to microvesicles in pancreatic beta-cells by palmitoylation in the NH2-terminal domain. J Cell Biol. 1992;118(2):309-320.

17. Vianello M, Tavolato B, Giometto B. Glutamic acid decarboxylase autoantibodies and neurological disorders. Neurol Sci. 2002;23(4):145-151.

18. Malter MP, Helmstaedter C, Urbach H, Vincent A, Bien CG. Antibodies to glutamic acid decarboxylase define a form of limbic encephalitis. Ann Neurol. 2010;67(4):470-478.

19. Akman CI, Patterson MC, Rubinstein A, Herzog R. Limbic encephalitis associated with anti-GAD antibody and common variable immune deficiency. Dev Med Child Neurol. 2009;51(7):563-567.

20. Dalmau J, Gleichman AJ, Hughes EG, Rossi JE, Peng X, Lai M, Dessain SK, et al. Anti-NMDA-receptor encephalitis: case series and analysis of the effects of antibodies. Lancet Neurol. 2008;7(12):1091-1098.

21. Mazzi G, Roia DD, Cruciatti B, Mata S, Catapano R. Plasma exchange for anti GAD associated non paraneoplastic limbic encephalitis. Transfus Apher Sci. 2008;39(3):229-233.

22. Saidha S, Murphy S, Ronayne A, McCarthy P, Hennessy MJ, Counihan T. Treatment of anti-glutamic acid decarboxylase antibody-associated limbic encephalitis with mycophenolate mofetil. J Neurol. 2010;257(6):10351038. 